\author{
УДК 616-001:004.94 \\ DOI: 10.26435/UC.V0I3(32).329
}

\author{
Ю.И. Стрельченко
}

ГОО ВПО «Донецкий национальный медицинский университет имени М. Горького», Донецк

\title{
МОДЕЛИРОВАНИЕ ТРАВМ РАЗЛИЧНОГО ГЕНЕЗА (СОБСТВЕННЫЕ РАЗРАБОТКИ И ОБЗОР ЛИТЕРАТУРЫ)
}

Донецкий регион всегда печально лидировал по уровню травматизма среди стран СНГ и Европы (производственный и дорожнотранспортный травматизм) (Ельский В.Н., 1994-2014; Зяблицев С.В., 2005-2014; Золотухин С.Е., 2000-2018) [1, 2]. Резко возросло количество травм в связи с продолжающимися боевыми действиями в Донбассе (OSCE, 20152018; Городник Г.А., 2015-2018; Золотухин С.Е., 2015-2018) [3]. Патогенез травматической болезни остаётся сложной и не до конца изученной проблемой, тем более что каждые три года научные данные устаревают, а каждые пять лет - пересматриваются. Для его изучения необходимы валидные модели травм различного генеза. Одной из актуальнейших проблем медицины Донбасса остаётся шахтный травматизм и взрывная шахтная травма. Однако характерные повреждения встречаются во всём мире и при террористических атаках (взрывы в закрытых пространствах, например, в метро), сейсмических стихийных бедствиях. Ведущее звено патогенеза взрывной шахтной травмы - синдром длительного раздавливания.

На данном этапе в литературе накопилось достаточно количество описанных моделей травм. Однако большинство исследователей уделяют внимание лишь одному виду травматизма (ожоговая, черепно-мозговая, электротравма) и лишь некоторые изучают политравму (Ельский В.Н., 1994-2014; Зяблицев С.В., 2005-2014; Золотухин C.Е., 2000-2018). Нами не найдено статей, в которых бы анализировались различные модели травмы в зависимости от их сильных и слабых сторон.

Кафедра патофизиологии Государственной образовательной организации высшего профессионального образования «Донецкий национальный медицинский университет имени М. Горького» вот уже более пятидесяти лет занимается изучением травмы различного генеза $[4,5]$. За это время накопился достаточный багаж знаний и моделей. Однако он слабо осве- щён в публикациях, так как методикам моделирования уделялось место лишь в главах диссертаций. На современном этапе развития доказательной медицины становится ясно, что экспериментальная модель должна быть воспроизводима в других лабораториях и методам моделирования сейчас уделяется большое внимание. В связи с этим автором были собраны разработанные на кафедре методы моделирования травм различного генеза для их дальнейшего анализа и сравнения с данными литературы. Автор владеет всеми описанными методиками, в некоторых является соавтором.

\section{ЦЕ Л b}

Проанализировать сильные (положительные) и слабые (отрицательные) стороны моделей травмы различного генеза.

\section{ОСНОВНАЯ ЧАСТЬ И ОБСУЖДЕНИЕ}

Были проанализированы и сравнены методики и модели травм различного генеза, разработанные на кафедре патологической физиологии и данные литературы.

Основная задача моделирования любой травмы - это стандартизация. Стандартизация синдрома длительного раздавливания была решена на кафедре патологической физиологии и в Научно-исследовательском институте травматологии и ортопедии (ныне Республиканский травматологический центр). Синдром длительного раздавливания моделировали раздавливанием мягких тканей задних конечностей крыс в течение четырёх часов в станках, предложенных В.Н. Ельским [1, 6, 7] с манометрическим контролем силы раздавливания (ключевой момент). Время четыре часа выбрано не случайно - это среднее время, проходящее от обрушения породы до освобождения бригадой горноспасателей пострадавшего из-под завала. Сила давления со-

(C) Ю.И. Стрельченко, 2019

(c) Университетская Клиника, 2019 
ставляла от четырёх до шести (в зависимости от необходимой тяжести шока) кг / см$^{2}$ на поверхность 12 см² $^{2}$ Данные показатели были подобраны эмпирически, так как они вызывали полный комплекс морфофункциональных изменений, характерных для травматического шока тяжелой степени с летальностью 75-80\% [8].

В некоторых исследованиях (С.Е. Золотухин и соавторы) для моделирования дополнительной эндогенной интоксикации накладывали турникет (лигатура из круглой резины) на область верхней трети передних конечностей крыс [1].

Также тяжелую механическую травму и шок моделировали с помощью модифицированного метода Кеннона (нанесение 50 ударов электромагнитным ударником по бедрам силой $\left.250 \mathrm{H} / \mathrm{cm}^{2}\right)[1]$.

По данным литературы [9] синдром длительного раздавливания моделируется на кроликах и собаках путем наложения жгута, затягивания тонкой резиновой трубки на конечности на длительный промежуток времени (восемь часов). Данный способ обладает существенными недостатками: трудность выполнения, множество подготовительных манипуляций, затруднение при снятии жгута с отекшей конечности животного и наличие странгуляционной борозды, в связи с чем не обеспечивается приближение модели к реальным условиям травмы. Также описаны способы моделирования синдрома длительного раздавливания с помощью хомутов различного размера [10]. Однако и при их использовании невозможно стандартизировать силу сдавления.

Моделирование комбинированной взрывной шахтной травмы представляет собой сложную техническую задачу, которая была решена на кафедре патологической физиологии (Г.К. Кривобок и соавторы) созданием модели, максимально приближённой к реальным производственным условиям [2]. Данная модель была испытана в Научно-исследовательском институте взрывозащищенного и рудничного электрооборудования с опытно-экспериментальным производством. Модель включала взрывную камеру с моделированием шахтных производственных факторов (ключевой момент), контузионную (в том числе черепно-мозговую), ожоговую и электрическую травму с токсическим компонентом (угольная пыль от 56 до 68 г/м³ , окись углерода $5 \%$, углекислый газ 5\%, метан от $8 \%$ до 8,4\%, продукты неполного сгорания цитотоксических ненасыщенных углеводородов).

Во время взрыва избыточное давление в камере составляло от 0,4 до 0,7 атм., температура пламени равнялась до $2000^{\circ} \mathrm{C}$ при экспозиции от 60 до 90 миллисекунд.
Внутри взрывной камеры располагались средства имитации шахтного микроклимата, устройство для моделирования шахтной преморбидной физической нагрузки в течение 90 минут (барабан-тредбан), сильфон (для моделирования отдельного контузионного компонента взрывной шахтной травмы) [11].

Электротравма моделировалась с помощью реле электрического тока, подающим напряжением 50 вольт, частотой 50 Гц и экспозицией в 1 секунду. Электрическими контактами служила медная решётка, на которой находилось животное $[12,13]$.

Ожоговый компонент взрывной шахтной травмы моделировался с помощью специального домика с отверстием, соответствующим от 5\% до $10 \%$ площади тела (именно такие ожоги по площади характерны для горнорабочих угольных шахт). Также был разработан специальный способ (Ю.И. Стрельченко и соавторы), позволяющий стандартизировать площадь и степень ожога (эпидермальные и поверхностные дермальные ожоги, также характерные для шахтных взрывов и аварий газового оборудования на производстве). Ожоги осуществляли открытым пламенем (газ пропан в смеси с кислородом, температура горения до 2000оС) с расстояния 15 мм и временем экспозиции три секунды, ожоговое повреждение составляло от 5\% до 10\% площади тела [14-17].

Для моделирования ожоговых поражений в литературе представлено множество вариантов термических агентов [18-21]: электромагнитное инфракрасное излучение, стеклянная пробирка с горячей водой, непосредственное погружение части тела животного в воду, нагретую до температуры $65-100^{\circ} \mathrm{C}$, сухой воздух с температурой $500^{\circ} \mathrm{C}$. Все приведенные способы не позволяют точно регулировать глубину и качество повреждения тканей, что ухудшает стандартизацию экспериментов и они далеки от реальных условий получения производственных ожогов. Некоторые способы сложны в воспроизведении и дорогостоящи (ожог лазером).

Черепно-мозговую травму на кафедре патофизиологии, а также в Центральной научноисследовательской лаборатории моделировали по методу С.В. Зяблицева. В Научноисследовательском институте травматологии и ортопедии (ныне Республиканский травматологический центр) - по методу С.Е. Золотухина с присоединением челюстной и челюстномозговой травмы (последняя модель практически не имеет интеллектуальных аналогов в литературе).

Согласно модели С.В. Зяблицева [22-24] груз заранее известной массы свободно падал вдоль 
направляющей трубки (диаметром 1 см и высотой 65 см), которая устанавливалась строго вертикально. Голова животного фиксировалась на полу из твердой резины. Груз падал на свод черепа животного строго в заданном месте. Площадь удара равнялась 0,5 см$^{2}$. Энергия удара зависела от массы груза и высоты, с которой падал груз. Таким образом, осуществлялась стандартизация методики - все животные получали одинаковую по силе удара и месту приложения силы травму.

Преимуществами метода являются, с одной стороны, простота и лёгкая воспроизводимость, а с другой - широкая возможность изменения степени тяжести травмы за счёт изменения силы удара. Последнее зависит от высоты и массы падающего груза. Для отработки оптимальной силы удара были подобраны пять грузов возрастающей массы (от 34,5 г до 98,5 г), которые при свободном падении с высоты 65 см развивали энергию удара от 0,22 Дж до 0,627 Дж. При этом энергия удара грузом № 3 массой 66,7 г составила 0,425 Дж, что вызвало при данной модели травмирования гибель 42,9\% животных за 48 часов после травмы (среднетяжелая черепномозговая травма).

При такой модели у животных имела место закрытая черепно-мозговая травма при наличии кожной гематомы и перелома костей свода черепа без смещения; тяжелой степени, с наличием размозжения коры теменных и височных долей (в зоне удара) и основы лобных и височных долей (в зоне «противоудара»); повреждения вещества головного мозга в виде диффузных мелкоточечных кровоизлияний; «оболочечной» гематомы в зоне удара.

По методике C.Е. Золотухина травму черепа моделировали нанесением одного удара с помощью пружинного ударника. Предварительно череп крысы фиксировали в специальном устройстве. Сила удара по черепу составляла $780 \mathrm{H} / \mathrm{cm}^{2}$ [25-28].

При отработке методики моделирования посттравматической реакции все параметры силы и частоты ударов подбирали экспериментально, изучая частоту летальности, продолжительность жизни и исследуя морфологические изменения в области травмы черепа и мозга крыс. На окончательном этапе разработки модели морфологические исследования показали, что при описанном способе моделирования черепно-мозговой травмы перелома костей черепа не наступает. Вскрытие головного мозга у животных через 4 часа после травмы выявляло наличие отдельных незначительных по размерам поднадкостничных, субдуральных, эпидуральных гематом. Гематом на основании черепа, участков размозжения мозговой ткани в области удара (коры и височных долей) и отека ткани гипофиза не было. В зоне противоудара - в основании лобных и височных долей мозга имелись незначительные повреждения в виде диффузных мелкоточечных кровоизлияний. В целом, травма мозга идентифицировалась как черепно-мозговой травмы легкой степени тяжести. Все крысы после травмы выживали (наблюдение два месяца).

Переломы костей нижней челюсти моделировали нанесением одного удара по защищенному черепу с помощью пружинного ударника. Предварительно череп крысы фиксировали в специальном устройстве. Сила удара по шлему составляла $1325 \mathrm{H} / \mathrm{cm}^{2}$. Увеличение силы удара по шлему на этой модели травмы, по сравнению с моделируемой черепно-мозговой травмой, было связано с необходимостью достижения цели двухстороннего перелома костей нижней челюсти крыс с вероятностью не менее $85 \%$. Большая чем $1325 \mathrm{H} / \mathrm{cm}^{2}$ сила удара по черепу увеличивала тяжесть черепно-мозговой травмы до уровня средней тяжести.

Сочетанную челюстно-мозговую травму моделировали с помощью уже описанного механизма. В самом механизме использовали пружину, которая обеспечивала силу удара по черепу, равную $780 \mathrm{H} / \mathrm{cm}^{2}$ (травма мозга). После воспроизведения повреждения череп крысы закрывали ватной прокладкой и шлемом, ставили более жесткую пружину ударного механизма, обеспечивающую силу удара, равную $1325 \mathrm{H} / \mathrm{cm}^{2}$, меняли мягкий валик на жесткий и снова с помощью ударного механизма производили удар (травма челюсти).

В литературных источниках описано несколько способов моделирования черепно-мозговых травм [24, 29]: жидкостно-перкуссионная травма мозга, модель контролируемого коркового повреждения, ударного ускорения и травма инерционного ускорения. Однако им присущи и существенные недостатки - недостаточная стандартизация, быстрое спонтанное восстановление функций головного мозга, повреждения чаще носят диффузный, а не локальный характер, технические сложности в моделировании травмы, и большая вероятность переломов черепа при моделировании тяжелой черепномозговой травмы. Само моделирование такими методиками отдалено от реальных условий получения черепно-мозговой травмы (скальпирование, трефинация, воздействие на твёрдую оболочку головного мозга).

\section{В Ы В О Д Ы}

Основные преимущества всех описанных моделей, разработанных на кафедре патофизиологии (в отличие от моделей, описанных в литера- 
туре) - это стандартизация методик по всем показателям и приближение их к реальным условиям получения травм на производстве, относительная простота в конструировании и использовании (исключение - модель взрывной шахт- ной травмы). Однако и её компоненты могут быть легко смоделированы по отдельности.

Надеемся, что данная работа будет полезна молодым исследователям для выбора той или иной модели травмы и лабораторного животного.

\section{Ю.И. Стрельченко}

ГОО ВПО «Донецкий национальный медицинский университет имени М. Горького», Донецк

\section{МОДЕЛИРОВАНИЕ ТРАВМ РАЗЛИЧНОГО ГЕНЕЗА (СОБСТВЕННЫЕ РАЗРАБОТКИ И ОБЗОР ЛИТЕРАТУРЫ)}

Данная статья посвящена обзору собственных разработок по моделированию травм различного генеза и их сравнение с данными литературы по этой же проблеме. Проведен анализ сильных (положительных) и слабых (отрицательных) сторон каждой модели. Надеемся, что данная работа будет полезна молодым исследователям для выбора той или иной модели травмы и лабораторного животного. В свою очередь, проведенный анализ показал, что большинство моделей не совсем адекватны реальным условиям че- ловеческого травматизма, тем более что полученные лабораторные показатели и методы терапии на лабораторных животных на современном этапе развития медицины практически нельзя интерпретировать на организм человека. Они лишь могут быть основанием для рекомендации к клинической апробации лекарственных препаратов.

Ключевые слова: травма, моделирование, патогенез.

\section{Y.I. Strelchenko}

SEI HPE «M. Gorky Donetsk National Medical University», Donetsk

\section{MODELING TRAUMAS OF VARIOUS GENESIS (OUR OWN DEVELOPMENTS AND LITERATURE REVIEW)}

This article is devoted to a review of our own developments in modeling traumas of various genesis and their comparison with literature data on the same problem. The analysis of the strengths (positive) and weak (negative) sides of each model was performed. We hope that this work will be useful to young researchers for choosing one or another model of trauma and a laboratory animal. In turn, the analysis showed that most of the models are not quite adequate to the real conditions of human traumas, especially since the obtained laboratory indicators and methods of therapy on laboratory animals at the present stage of development of medicine cannot practically be interpreted on the human body. They can only be the basis for recommending clinical trials of drugs.

Key words: trauma, modeling, pathogenesis.

\section{ЛИТЕРАТУРА}

1. Ельский В.Н., Климовицкий В.Г., Золотухин С.Е., Крюк Ю.Я., Шпаченко Н.Н., Длугоканский Д.М., Ельский А.В. Избранные аспекты патогенеза и лечения травматической болезни. Донецк; 2002. 359.

2. Ельский В.Н., Гусак В.К., Кривобок Г.К., Талалаенко А.Н., Фисталь Э.Я. Взрывная шахтная травма. Донецк; 2002. 170.

3. Городник Г.А. Патогенез боевой травмы (обзор литературных данных). Архив клинической и экспериментальной медицины. 2015; 24 (1): 51-57.

4. Ельский В.Н., Зяблицев С.В., Крюк Ю.Я., Кривобок Г.К., Золотухин С.Е., Колесникова С.В., Пищулина С.В., Антонов Е.В., Сидун М.С., Заведея Т.Л., Стрельченко Ю.И. Патофизиология травмы (обзор экспериментального коллективного исследования проблемы за 40 лет). Вісник морфології. 2015; 21 (1): 242-251.

5. Ельский В.Н., Крюк Ю.Я., Кривобок Г.К., Золотухин С.Е.,

\section{REFERENCES}

1. El'skii V.N., Klimovitskii V.G., Zolotukhin S.E., Kryuk Yu.Ya., Shpachenko N.N., Dlugokanskii D.M., El'skii A.V. Izbrannye aspekty patogeneza i lecheniya travmaticheskoi bolezni. Donetsk; 2002. 359 (in Russian).

2. El'skii V.N., Gusak V.K., Krivobok G.K., Talalaenko A.N., Fistal' E.Ya. Vzryvnaya shakhtnaya travma. Donetsk; 2002. 170 (in Russian).

3. Gorodnik G.A. Patogenez boevoi travmy (obzor literaturnykh dannykh). Arkhiv klinicheskoi i eksperimental'noi meditsiny. 2015; 24 (1): 51-57 (in Russian).

4. El'skii V.N., Zyablitsev S.V., Kryuk Yu.Ya., Krivobok G.K., Zolotukhin S.E., Kolesnikova S.V., Pishchulina S.V., Antonov E.V., Sidun M.S., Zavedeya T.L., Strel'chenko Yu.I. Patofiziologiya travmy (obzor eksperimental'nogo kollektivnogo issledovaniya problemy za 40 let). Visnik morfologiï. 2015; 21 (1): 242-251 (in Russian).

5. El'skii V.N., Kryuk Yu.Ya., Krivobok G.K., Zolotukhin S.E., 
Пищулина С.В., Сидун М.С., Заведея Т.Л., Стрельченко Ю.И. Экспериментальное коллективное исследование патофизиологии травмы за 40 лет. Университетская клиника. 2016; 12 (1): 65-69.

6. Ельский В.Н., Колесникова С.В., Стрельченко Ю.И. Методы и экспериментальное исследование влияния введения липосом у интактных животных. В кн.: Патогенетическая коррекция нанопрепаратом липосом липидной пероксидации при синдроме длительного раздавливания. Донецк: «Каштан»; 2012: 52-61.

7. Нигуляну В.И., Ельский В.Н., Криворучко Б.И., Зорькин А.А. Синдром длительного раздавливания. Кишинев: Штиинца; 1984. 222.

8. Зябліцев С.В., Єльський В.М., Стрельченко Ю.І., Піщуліна С.В. Механізми і стадійність порушень, які зумовлюють розвиток синдрому ендогенної інтоксикації. Вісник морфології. 2014; 20 (2): 318-324.

9. Туркменов М.Т. Принципы физиологического моделирования и результаты изучения некоторых угрожающих состояний в эксперименте. Фрунзе: «Илим»; 1975: 87-88.

10. Исмагилов Ф.А. Патент RU 2341831 G09B23/28. Способ моделирования синдрома длительного раздавливания у лабораторных животных; 2001.

11. Смолякова Т.В., Стрельченко Ю.І. Удосконалення пристрою для дослідження впливу змін барометричного тиску на організм. Первый независимый научный вестник. 2015; 5: 17-20.

12. Ельский В.Н., Кривобок А.Г., Антонов Е.В. и др. Системная гемодинамика при комбинированном действии факторов шахтного взрыва и электрического тока в эксперименте. Медицинский вестник Башкортостана. 2009; 4 (2): 80-83.

13. Єльський В.М., Кривобок Г.К., Бондаренко Н.М. та ін. Вплив електричного струму на системну гемодинаміку при експериментальній вибуховій шахтній травмі. Питання експериментальної та клінічної медицини (збірник статей). 2010; 14 (2): 165-169.

14. Єльський В.М., Кривобок Г.К., Крюк Ю.Я. та ін. Патент Украины на полезную модель № 52390. Спосіб моделювання дозованого термічного опіку МПК G09B 23/28 (2006.01); 2010.

15. Стрельченко Ю.І., Антонов Є.В., Колеснікова С.В. Моделювання виробничих термічних опіків. Питання експериментальної та клінічної медицини (збірник статей). 2012; 16 (2): 128-132.

16. Єльський В.М., Кривобок Г.К., Стрельченко Ю.І. Моделювання дозованого термічного опіку у лабораторних тварин для розробки ефективних методівлікування. Питання судової медицини та експертної практики. 2010; 10: 102-104.

17. Strelchenko Yu.I., Linchevskaya L.P., Bondarenko N.N., Pishulina S.V. Thermal burns and state of central nervous and neuroendocrine systems by the polarized-light influence. Университетская клиника. 2015; 11 (1): 7578.

18. Андреев С.В. Моделирование заболеваний. Москва: Медицина; 1973. 336.

19. Шарлот Ю.М., Карханин Н.П., Борский О.Б., Зюзьгин Н.И. Патент РФ № 2027143 на изобретение. Устройство для моделирования термического ожога у лабораторных животных; 2001.

20. Моновцов И.А., Лазаренко В.А., Блинков Ю.Ю., Лазарев Е.В. Патент РФ 2210118. Способ моделирования ожоговой травмы в эксперименте у животных; 08.10.01.

21. Колсанов А.В., Алипов В.В., Лебедев М.С., Добрейкин Е.А., Лимарева Л.В. Патент РФ 2472232. Способ моделирования термической ожоговой раны кожи у лабораторных животных; 24.03.11.

22. Jelsky V., Zyablitsev S., Strelchenko I. et al. The critical terms of cranial-cerebral traumatic illness course. Journal of Neurotrauma. Abstracts from the 11th-Symposium of the International Neurotrauma society. 2014, March 1923. Budapest; 2014: 15.

23. Ziablitsev S.V., Elskyy V.N., Pischulina S.V., Strelchenko
Pishchulina S.V., Sidun M.S., Zavedeya T.L, Strel'chenko Yu.I. Eksperimental'noe kollektivnoe issledovanie patofiziologii travmy za 40 let. Universitetskaya klinika. 2016; 12 (1): 65-69 (in Russian).

6. El'skii V.N., Kolesnikova S.V., Strel'chenko Yu.I. Metody i eksperimental'noe issledovanie vliyaniya vvedeniya liposom $\mathrm{u}$ intaktnykh zhivotnykh. V kn.: Patogeneticheskaya korrektsiya nanopreparatom liposom lipidnoi peroksidatsii pri sindrome dlitel'nogo razdavlivaniya. Donetsk: «Kashtan»; 2012: 52-61 (in Russian).

7. Nigulyanu V.I., El'skii V.N., Krivoruchko B.I., Zor'kin A.A. Sindrom dlitel'nogo razdavlivaniya. Kishinev: Shtiintsa; 1984. 222 (in Russian).

8. Zyablitsev S.V., El's'kii V.M., Strel'chenko Yu.I., Pishchulina S.V. Mekhanizmi i stadiinist' porushen', yaki zumovlyuyut' rozvitok sindromu endogennoï intoksikatsii. Visnik morfologiï. 2014; 20 (2): 318-324 (in Ukrainian).

9. Turkmenov M.T. Printsipy fiziologicheskogo modelirovaniya i rezul'taty izucheniya nekotorykh ugrozhayushchikh sostoyanii v eksperimente. Frunze: «Ilim»; 1975: 8788 (in Russian).

10. Ismagilov F.A. Patent RU 2341831 G09B23/28. Sposob modelirovaniya sindroma dlitel'nogo razdavlivaniya u laboratornykh zhivotnykh; 2001 (in Russian).

11. Smolyakova T.V., Strel'chenko Yu.I. Udoskonalennya pristroyu dlya doslidzhennya vplivu zmin barometrichnogo tisku na organizm. Pervyi nezavisimyi nauchnyi vestnik. 2015; 5: 17-20 (in Ukrainian).

12. El'skii V.N., Krivobok A.G., Antonov E.V. i dr. Sistemnaya gemodinamika pri kombinirovannom deistvii faktorov shakhtnogo vzryva i elektricheskogo toka v eksperimente. Meditsinskii vestnik Bashkortostana. 2009; 4 (2): 80-83 (in Russian).

13. El's'kii V.M., Krivobok G.K., Bondarenko N.M. ta in. Vpliv elektrichnogo strumu na sistemnu gemodinamiku pri eksperimental'nii vibukhovii shakhtnii travmi. Pitannya eksperimental'noï ta klinichnoï meditsini (zbirnik statei). 2010; 14 (2): 165-169 (in Ukrainian).

14. El's'kii V.M., Krivobok G.K., Kryuk Yu.Ya. ta in. Patent Ukrainy na poleznuyu model' № 52390. Sposib modelyuvannya dozovanogo termichnogo opiku MPK G09B 23/28 (2006.01); 2010 (in Ukrainian).

15. Strel'chenko Yu.I., Antonov E.V., Kolesnikova S.V. Modelyuvannya virobnichikh termichnikh opikiv. Pitannya eksperimental'noï ta klinichnoï meditsini (zbirnik statei). 2012; 16 (2): 128-132 (in Ukrainian).

16. El's'kii V.M., Krivobok G.K., Strel'chenko Yu.I. Modelyuvannya dozovanogo termichnogo opiku u laboratornikh tvarin dlya rozrobki efektivnikh metodivlikuvannya. Pitannya sudovoï meditsini ta ekspertnoï praktiki. 2010; 10: 102-104 (in Ukrainian).

17. Strelchenko Yu.I., Linchevskaya L.P., Bondarenko N.N., Pishulina S.V. Thermal burns and state of central nervous and neuroendocrine systems by the polarized-light influence. Universitetskaya klinika. 2015; 11 (1): 75-78.

18. Andreev S.V. Modelirovanie zabolevanii. Moskva: Meditsina; 1973. 336 (in Russian).

19. Sharlot Yu.M., Karkhanin N.P., Borskii O.B., Zyuz'gin N.I. Patent RF № 2027143 na izobretenie. Ustroistvo dlya modelirovaniya termicheskogo ozhoga $\mathrm{u}$ laboratornykh zhivotnykh; 2001 (in Russian).

20. Monovtsov I.A., Lazarenko V.A., Blinkov Yu.Yu., Lazarev E.V. Patent RF 2210118. Sposob modelirovaniya ozhogovoi travmy v eksperimente u zhivotnykh; 08.10.01. (in Russian)

21. Kolsanov A.V., Alipov V.V., Lebedev M.S., Dobreikin E.A., Limareva L.V. Patent RF 2472232. Sposob modelirovaniya termicheskoi ozhogovoi rany kozhi u laboratornykh zhivotnykh; 24.03.11. (in Russian)

22. Jelsky V., Zyablitsev S., Strelchenko I. et al. The critical terms of cranial-cerebral traumatic illness course. Journal of Neurotrauma. Abstracts from the 11th-Symposium of the International Neurotrauma society. 2014, March 1923. Budapest; 2014: 15

23. Ziablitsev S.V., Elskyy V.N., Pischulina S.V., Strelchenko U.I., Antonov E.V., Sudilovskaya U.L., Khudoley S.A.. 
U.I, Antonov E.V., Sudilovskaya U.L., Khudoley S.A.. The dynamics of biochemical markers of enzymoemia and middle-weight molecules in the early post-traumatic period of brain injury. Journal of Health Sciences. 2014; 04 (01): 297-302.

24. Ельский В.Н., Зяблицев С.В. Моделирование черепномозговой травмы. Донецк: «Новый мир»; 2008. 140.

25. Стрельченко Ю.И., Пономаренко Т.В. Экспериментальное обоснование применения кверцитина при черепно-мозговой травме. Доброхотовские чтения: Материалы II междисциплинарной научной конференции. Махачкала; 2017: 170-173.

26. Крюк Ю.Я., Ельский В.Н., Линчевская Л.П., Бондаренко Н.Н., Пищулина С.В., Стрельченко Ю.И., Фабер А.И., Есаулов А.Д. Эффективность миакальцика при лечении остеопоретических крыс с тяжелой черепномозговой травмой по данным изменения отдельных показателей кальциевого обмена и цитокинов. Актуальные вопросы реабилитологии и педагогики: сборник научных трудов. 2018; 4 (2): 247-257.

27. Крюк Ю.Я., Золотухин С.Е., Стрельченко Ю.И., Нечепорчук А.В. Экспериментальная черепно-мозговая травма и фармакотерапия кверцитином. Университетская клиника. 2015; 11 (2): 47-51.

28. Крюк Ю.Я., Золотухин С.Е., Стрельченко Ю.И., Нечепорчук А.В. Черепно-мозговая травма и фармакотерапия кверцитином. Архив клинической и экспериментальной медицины. 2015; 24 (1): 30-33.

29. Радьков И.В., Лаптев В.В., Плехова Н.Г. Технологии моделирования диффузной черепно-мозговой травмы. Современные проблемы науки и образования. 2018; 4. URL: http://www.science-education.ru/ru/article/ view?id=27744
The dynamics of biochemical markers of enzymoemia and middle-weight molecules in the early post-traumatic period of brain injury. Journal of Health Sciences. 2014; 04 (01): 297-302.

24. El'skii V.N., Zyablitsev S.V. Modelirovanie cherepnomozgovoi travmy. Donetsk: «Novyi mir»; 2008. 140 (in Russian).

25. Strel'chenko Yu.I., Ponomarenko T.V. Eksperimental'noe obosnovanie primeneniya kvertsitina pri cherepnomozgovoi travme. Dobrokhotovskie chteniya: Materialy II mezhdistsiplinarnoi nauchnoi konferentsii. Makhachkala; 2017: 170-173 (in Russian).

26. Kryuk Yu.Ya., El'skii V.N., Linchevskaya L.P., Bondarenko N.N., Pishchulina S.V., Strel'chenko Yu.I., Faber A.I., Esaulov A.D. Effektivnost' miakal'tsika pri lechenii osteoporeticheskikh krys s tyazheloi cherepno-mozgovoi travmoi po dannym izmeneniya otdel'nykh pokazatelei kal'tsievogo obmena i tsitokinov. Aktual'nye voprosy reabilitologii i pedagogiki: sbornik nauchnykh trudov. 2018; 4 (2): 247257 (in Russian).

27. Kryuk Yu.Ya., Zolotukhin S.E., Strel'chenko Yu.I., Necheporchuk A.V. Eksperimental'naya cherepno-mozgovaya travma i farmakoterapiya kvertsitinom. Universitetskaya klinika. 2015; 11 (2): 47-51 (in Russian).

28. Kryuk Yu.Ya.,Zolotukhin S.E., Strel'chenko Yu.I., Necheporchuk A.V. Cherepno-mozgovaya travma i farmakoterapiya kvertsitinom. Arkhiv klinicheskoi i eksperimental'noi meditsiny. 2015; 24 (1): 30-33 (in Russian).

29. Rad'kov I.V., Laptev V.V., Plekhova N.G. Tekhnologii modelirovaniya diffuznoi cherepno-mozgovoi travmy. Sovremennye problemy nauki i obrazovaniya. 2018; 4. URL: http://www.science-education.ru/ru/article/ view?id=27744 (in Russian). 